\title{
Sichere Praxis - was die Kripo rät
}

Ob Bargeld, Rezeptblöcke, Hightech-Geräte, sensible Patientendaten oder Medikamente

- für Diebe gibt es in Praxen einiges zu holen. Da lohnt es sich, über den richtigen

Einbruchschutz nachzudenken. Eine Festung muss aber nicht errichtet werden.

$\mathrm{E}$ in Arzt mit einer Praxis im Parterre sagte, ihm gefielen keine Gitter, „das wirke auf Patienten abschreckend“, berichtet Angelika Fritsche, Kriminalhauptkommissarin in Hamburg. „Ich habe ihm geraten, es seinen Kollegen im mediterranen Raum gleichzutun: Nach der Sprechstunde wird nun ein Gitter von oben heruntergezogen und verschließt den Eingang zur Praxis.“

Die Expertin berät in der Kriminalpolizeilichen Beratungsstelle Hamburg, einer Einrichtung, die viele deutsche Polizeien anbieten. Hier können sich Ärzte individuelle, auf ihre Praxis zugeschnittene Informationen einholen, auch über zertifizierte Produkte und Spezialfirmen, die diese Sicherheitstechnik vorschriftsmäßig einbauen. „Zunächst unterscheidet man, neben organisatorischen Maßnahmen, die zwei großen Bereiche mechanische Sicherung und Alarmtechnik“, so Fritsche.

\section{Jede Praxis kann sicher sein}

Fenster und Türen, die schwer aufzubrechen sind - aufhebeln oder einschlagen wäre aufgrund des Materials und der Verarbeitung langwierig und lärmintensiv - oder auch komplette Schließsysteme sind in sogenannte Widerstandsklassen von 1 bis 6 eingeteilt: WK 2 etwa erschwert dem Gelegenheitstäter das Eindringen, WK 3 und höher vermasselt sogar dem Profi die Tour.

„Idealerweise werden Sicherungsmaßnahmen schon beim Praxisbau bedacht, was sich oft kostengünstiger darstellt. Aber wir beraten auch viele Ärzte, die Ihre Räume nachrüsten wollen", so die Expertin der Polizei.

Der zweite, große Bereich ist die Alarmtechnik. Versuchen Personen einzudringen oder sind schon in den Praxisräumen, „sollte eine Alarmmeldung über eine Serviceleitstelle bei einem Wachunternehmen oder der Polizei eingehen“, erklärt Fritsche. Die Planung und Installation einer Überfallmeldeanlage (ÜMA) oder Einbruchmeldeanlage (EMA) sollte so erfolgen, dass bei einem Einbruchversuch der Alarm ausgelöst wird, bevor Einbrecher die Sicherungseinrichtungen überwunden haben.

Da jede örtliche Situation ganz spezifische Schutzvorkehrungen erfordert, rät Fritsche, den Service der kriminalpolizeilichen Beratungsstellen in Anspruch zu nehmen. Fachleute zeigen - auch gern direkt vor Ort in der Praxis - Schwachstellen auf und erläutern konkret, wie sich der Einbruchschutz durch geeignete Sicherungs- und Überwachungstechnik verbessern lässt.

Die Adresse der zuständigen Beratungsstellen erfährt man bei der örtlichen Polizeidienststelle und auf der Internetseite der Polizei. Dort gibt es auch wichtige Informationen zum Einbruchsschutz (www.polizei-beratung.de). Ein aktuelles, bundesweites Verzeichnis zertifizierter Hersteller hat die bayerische Polizei zusammengestellt (www.polizei.bayern.de).

Sabine Henßen

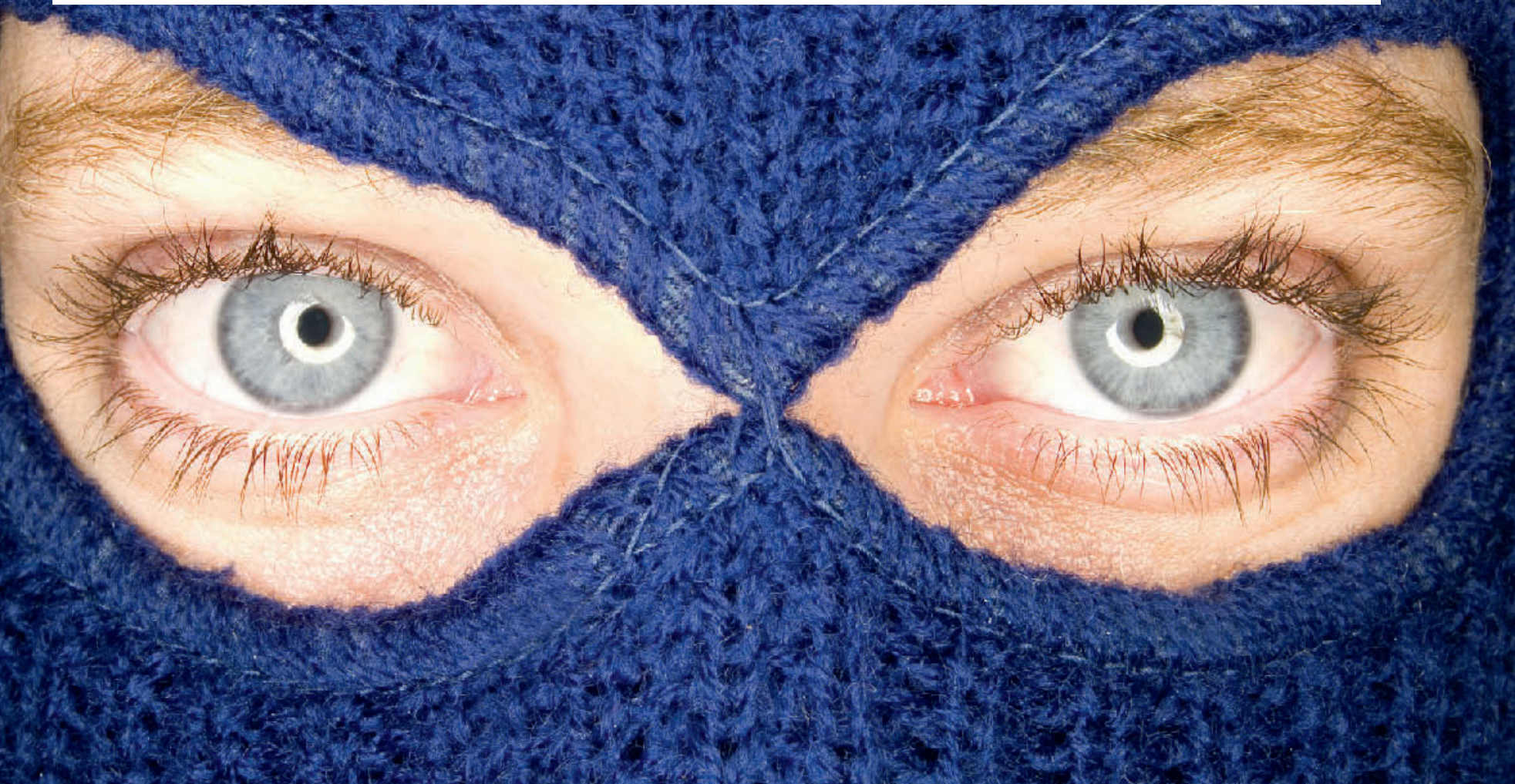

